Institute of Internet and Intelligent Technologies on Automation and Robotics in Construction

Vilnius Gediminas Technical University

June 26-29, 2008

Saulètekio al. 11, 10223 Vilnius, Lithuania

http://www.isarc2008.vgtu.lt/

ISARC-2008

\title{
DEVELOPMENT OF A LIFE CYCLE COSTING SYSTEM FOR LIGHT RAIL TRANSIT CONSTRUCTION PROJECTS
}

\author{
Gu-Taek Kim \\ Chief Operation Officer in Cospec Information \\ Co.,Ltd. \\ 3F, GeabMok Bldg., 1427-6 Seocho-1 Dong, \\ Seocho-Gu, Seoul, 137-864, Korea \\ gutag@cospec.co.kr

\section{Du-Heon Lee} \\ Researcher in Korea Institute of Construction \\ Technology \\ 2311 daehwa-Dong, Ilsanseo-Gu, Goyang-Si, \\ Gyeonggi-Do 411-712, Korea \\ 1dh24@kict.re.kr

\section{Hyun-Bae Kim} \\ Vice President of R\&D Center in Posco E\&C

$$
\text { Co.,Ltd }
$$ \\ 75-9 Youngchon-Ri, dongtan-Myeon, Hwaseong- \\ Si, Gyeonggi-Do 445-810, Korea \\ kimhb@poscoenc.com
}

\section{Kyoon-Tai Kim}

Senior Researcher in Korea Institute of Construction Technology, Ph.D. (designated presenter)

2311 daehwa-Dong, Ilsanseo-Gu, Goyang-Si, Gyeonggi-Do 411-712, Korea ktkim@kict.re.kr

\section{Choong-Hee Han}

Professor in Kyunghee Univ., Ph.D.

Seocheon-Dong, Giheung-Gu, Yongin-si, Gyeonggi-do 446-701 Korea chhan@khu.ac.kr

\section{Jin-Taek Jun}

Section Manager of R\&D Center in Posco E\&C Co.,Ltd

75-9 Youngchon-Ri, dongtan-Myeon, HwaseongSi, Gyeonggi-Do 445-810, Korea jtjun@poscoenc.com

\begin{abstract}
The need for Light Rail Transit (LRT) in Korea has substantially increased as a result of the heavy traffic congestion in large cities such as Seoul. In Korea, most of the LRT construction projects have been achieved with the help of private sector investment, and the private sector companies that wished to participate in such projects had to make a rapid decision regarding their participation by conducting a thorough economic analysis before the beginning of the project. In other words, to ensure the success of the project, would-be participants had to estimate the precise amount of certain Life Cycle Costs (LCC), such as initial investment costs (construction cost) and maintenance costs. Experience, historical data, and know-how regarding previous LRT construction projects were needed to estimate the LCC of the project, but the private sector in Korea lacks the historical data and proper systems to support such decision-making.

In this research, a life cycle costing system for the LRT construction project was developed to support feasibility studies on such projects. Construction cost was determined by the type of structure, its scale, and the methods of construction, so the
\end{abstract}


factors related to the construction cost had to be defined in advance, and a database that included related historical data also had to be built. In this project, the main factors that influence structures such as bridges and tunnels are defined, and a database related to unit costs is built based on the existing studies and databases. The LCC analysis process and the LCC model of LRT are defined through a study of existing research. An algorithm for the LCC analysis of LRT was made through a study on the analysis of uncertainty factors and cost breakdown structures that are adaptable to LRT. The developed system, which analyzes the construction cost and LCC cash flow, can considerably improve the efficiency of LRT LCC analysis.

\section{KEYWORDS}

Life Cycle Cost (LCC), Cost Breakdown Structure (CBS), Light Rail Transit (LRT), Economic Evaluation

\section{INTRODUCTION}

\subsection{Background and Objective}

The need for Light Rail Transit (LRT) in Korea has recently been on the rise. Typically, an LRT construction project in Korea is usually undertaken in the form of a private business (BTL method: Building Transfer Lease method), so a private company should thus conduct an economic analysis in advance, including a quickly-derived and accurate calculation of the life cycle cost (LCC) of the LRT in which it wants to participate. Business success largely depends on accurate estimates, such as the initial investment cost from the design stage to construction stage, the operation cost required for operation and maintenance stages, and the profits collected in the operation stage. In order to more accurately estimate LCC, there are several factors needed, including a range of construction experience, performance data, and related expertise; however, the current reality is that companies in Korea generally make such estimations based on highly inaccurate data, due to the fact that there is almost a complete lack of related construction experience, and insufficient performance data.

This paper presents an economic analysis system for civil structures of LRT by taking into account the automatic cost estimating system for a range of LRT structures (bridges, tunnels, etc). Based on this, our objective with this study is to provide a resource for companies making a decision regarding their potential participation in an LRT construction project, by analyzing the LCC of a bridge in an LRT.

\subsection{Scope and Methodology}

It is impossible for a company to analyze and review actual data relating to LRTs in Korea, because there have been no previous cases where LRTs have been utilized. Cases of LRTs being implemented in foreign countries can be reviewed, but it is very difficult to process this data into an appropriate form for systematization. Therefore, the factors necessary for a feasibility analysis were derived from existing domestic studies on the construction of structures that can be classified as appropriate for LRT.

By utilizing the factors drawn from the conventional studies, construction cost will be automatically estimated when a user selects the type of structure, and the size and method of construction. In addition, the algorithm for the LCC analysis was written by reviewing the cost classification system and the factors of precariousness. The LRT-LCC (LRT Life Cycle Cost) System was realized based on this process.

\section{PRELIMINARY CONSIDERATIONS}

\subsection{Domestic and Overseas LCC Analysis Programs}

Conventional LCC analysis programs were reviewed to utilize data for the development of a new system. This is the first effort ever made to develop an LCC analysis program for LRTs in Korea.

\section{(1) Bridge LCC}

Bridge LCC (Bridge Life Cycle Cost for Preliminary Bridge Design) was developed by the Building and Fire Research Laboratory Office of Applied Economics, an affiliated organization of the National Institute of Science and Technology (NIST). Version 
1.0 was developed in 1999, and Version 2.0 was released in 2000 .

\section{(2) BLCCA}

BLCCA (Bridge Life Cycle Cost Analysis) was developed based on the LCC Analysis Procedure and Method established by Hawk of Delcon under the NCHRP support by Transportation Research Board under National Research Council and National Science Foundation in 1998, and BLCCA 1.0 LCC Analysis Software was released.

\section{(3) HDM}

HDM-4 (Highway Development \& Management, 2000) was developed with the financial support of several organizations, such as the Asian Development Bank (ADB), the Department for International Development in the United Kingdom (DFID), the Swedish National Road Administration (SNRA), the World Bank, and others.

This program is a tool that can analyze an investment project on road facility from a technological and an economic perspective.

\subsection{LCC Analysis of Light Rail Transit}

In this paper, the level-of-detail of input variables used for cost estimation was applied differently. Depending on the stage of design, there are many differences in the data that can be input to perform the LCC analysis, and thus, the analysis is performed by dividing the entire process into predesign and post-design stages.

\section{(1) Pre-design Stage}

There is not sufficient data on the actual construction of LRTs in Korea, and thus we used the standard construction costs used for railroads in order to calculate the initial standard construction cost. Based on the 'Investment Analysis on Railroad and Revised Evaluation Manual' drawn up by Korea Railroad in 2003, we estimated construction cost in accordance with the following classifications (See Table 1).

The maintenance costs estimated showed large differences according to the system. Though different systems may have been produced by the same company, the costs can differ according to the tools used and the year of production, and accordingly it is very difficult to draw costs that are coherent to each other. In the OO Light Rail Transit Implementation Plan, Korea Transport Institute calculated and utilized maintenance costs by dividing costs into station cost, train cost and system cost. In this study, the station maintenance cost was estimated by applying the deflator used in the construction industry.

(2) Post-design Stage

In the study on the Life Cycle Cost Analysis of Railroad Bridges conducted in 2006, Du-heon Lee $[1,2]$ classified bridge structures and studied a method to calculate initial investment cost and maintenance cost, in order to perform an LCC analysis of railroad bridge structures.

In this study, we utilized the cost classification system in order to implement the LCC analysis of railroad bridge structures (See Figure 1).

Initial investment costs for a bridge are estimated depending on the superstructure of a bridge, as shown in Table 2. Maintenance application cycle and cost are calculated as shown in Table 3 . The results were utilized to perform LCC analysis of bridge structures

In estimating the LCC of an LRT, structures considered other than bridges included tunnels, civil structures and buildings. To develop the LRT-LCC system, we referred to several studies including, 'A Study on Domestic and Overseas Concrete Orbit Life Cycle Cost Analysis', which was conducted by Korea Rail Network Authority in 2006; 'Revision and Supplement Study of Standard Guidelines for Preliminary Feasibility Research on Road and Railroad Business (4 $4^{\text {th }}$ edition)', which was performed by Korea Expressway Corporation in 2000, and the 'Railroad Investment Analysis and Revised Evaluation Manual' to utilize LCC analysis factors and calculation methods for tunnels, civil structures, and buildings (train stations). 
Table 1. Standard Railroad Construction Cost (Source: Korea Railroad)

\begin{tabular}{|c|c|c|c|c|c|}
\hline \multirow{2}{*}{\multicolumn{3}{|c|}{ Division }} & \multicolumn{2}{|c|}{ Double-track Electrification } & \multirow{2}{*}{ Remarks } \\
\hline & & & General & Urban & \\
\hline \multicolumn{3}{|c|}{ 1. Cost of facility } & 240 & 333 & \\
\hline \multirow{10}{*}{$\begin{array}{l}\text { Uू } \\
\text { ص̆ }\end{array}$} & & Average & 173 & 252 & \\
\hline & \multirow{2}{*}{ Civil work } & General Ground & 82 & 115 & \\
\hline & & Soft Ground & 111 & 155 & \\
\hline & \multirow{3}{*}{ Bridge } & Over bridge & 75 & 75 & \\
\hline & & General Ground & 227 & 318 & \\
\hline & & Soft Ground & 283 & 396 & \\
\hline & \multirow{2}{*}{ Tunnel } & Mountainous Tunnel & 172 & 241 & \\
\hline & & Metropolitan Tunnel & 202 & 283 & \\
\hline & \multirow{2}{*}{ Station } & Civil work & 78 & 109 & Per place \\
\hline & & Bridge & 369 & 517 & Per place \\
\hline \multicolumn{3}{|c|}{ - Orbit } & 14 & 17 & \\
\hline \multicolumn{3}{|c|}{ - Building } & 16 & 24 & \\
\hline \multicolumn{3}{|c|}{ - Electric power } & 5 & 5 & \\
\hline \multicolumn{3}{|c|}{ - Signal } & 9 & 9 & \\
\hline \multicolumn{3}{|c|}{ - Communication } & 7 & 10 & \\
\hline \multicolumn{3}{|c|}{ - Streetcar line } & 16 & 16 & Substation not reflected \\
\hline \multicolumn{3}{|c|}{ 2. Incidental expenses } & 19 & 27 & 8.1 percent of the cost of facility \\
\hline \multicolumn{3}{|c|}{ 3. Land cost } & 23 & 53 & \\
\hline & & Total & 282 & 413 & \\
\hline
\end{tabular}

Table 2. Initial Investment Cost depending on the Superstructure of a Bridge (Source: Du-heon Lee, 2006)

\begin{tabular}{|c|c|c|c|}
\hline Type & Applied length & Construction Cost & Applied Condition \\
\hline $\begin{array}{c}\text { PSC } \\
\text { BEAM }\end{array}$ & $20.0 \mathrm{~m}-25.0 \mathrm{~m}$ & $\begin{array}{l}\text { Superstructure: KRW6.292 Million/m } \\
\text { Substructure: KRW5.698 Million/m } \\
\text { Total construction cost: KRW 11.99Million/m }\end{array}$ & -Standard section \\
\hline $\begin{array}{c}\text { IPC } \\
\text { GIRDER }\end{array}$ & $30.0 \mathrm{~m}-35.0 \mathrm{~m}$ & $\begin{array}{l}\text { Superstructure: KRW 10.03 Million /m } \\
\text { Substructure: KRW 7.58 Million /m } \\
\text { Total construction cost: KRW } 17.61 \text { Million/m }\end{array}$ & $\begin{array}{l}\cdot \text { Standard section } \\
\cdot \text { Section required under-bridge height } \\
\text { and double span }\end{array}$ \\
\hline $\begin{array}{c}\text { PPC } \\
\text { GIRDER }\end{array}$ & $20.0 \mathrm{~m}-35.0 \mathrm{~m}$ & $\begin{array}{l}\text { Superstructure: KRW10.90 Million/m } \\
\text { Substructure: KRW } 7.58 \text { Million /m } \\
\text { Total construction cost: KRW } 18.48 \text { Million /m }\end{array}$ & $\begin{array}{l}\text { - Standard section } \\
\cdot \text { Section required under-bridge height } \\
\text { and double span }\end{array}$ \\
\hline $\begin{array}{l}\text { U- } \\
\text { GIRDER }\end{array}$ & $30.0 \mathrm{~m}-35.0 \mathrm{~m}$ & $\begin{array}{l}\text { Superstructure: KRW 11.37 Million /m } \\
\text { Substructure: KRW 6.94 Million /m } \\
\text { Total construction cost: KRW 18.31 Million /m }\end{array}$ & - Standard section \\
\hline $\begin{array}{l}\text { PF } \\
\text { BEAM }\end{array}$ & $30.0 \mathrm{~m}-35.0 \mathrm{~m}$ & $\begin{array}{l}\text { Superstructure: KRW 21.80 Million /m } \\
\text { Substructure: KRW 7.58 Million /m } \\
\text { Total construction cost: KRW 28.70 Million /m }\end{array}$ & $\begin{array}{l}\text { Section required under-bridge height } \\
\text { and double span }\end{array}$ \\
\hline $\begin{array}{c}\text { RPF } \\
\text { BEAM }\end{array}$ & $30.0 \mathrm{~m}-35.0 \mathrm{~m}$ & $\begin{array}{l}\text { Superstructure: KRW 19.03 Million /m } \\
\text { Substructure: KRW 8.11 Million /m } \\
\text { Total construction cost: KRW 27.14 Million /m }\end{array}$ & $\begin{array}{l}\text { Section required under-bridge height } \\
\text { and double span }\end{array}$ \\
\hline
\end{tabular}




\begin{tabular}{|c|c|c|c|}
\hline Type & Applied length & Construction Cost & Applied Condition \\
\hline $\begin{array}{l}\text { STEEL } \\
\text { BOX } \\
\text { GIRDER }\end{array}$ & $40.0 \mathrm{~m}-50.0 \mathrm{~m}$ & $\begin{array}{l}\text { Superstructure: KRW } 16.41 \text { Million /m } \\
\text { Substructure: KRW 9.46 Million /m } \\
\text { Total construction cost: KRW } 25.87 \text { Million/m }\end{array}$ & - Cross section of stream and road \\
\hline $\begin{array}{c}\text { PSC } \\
\text { BOX } \\
\text { GIRDER } \\
\end{array}$ & $40.0 \mathrm{~m}-50.0 \mathrm{~m}$ & $\begin{array}{l}\text { Superstructure: KRW 16.41 Million /m } \\
\text { Substructure: KRW 9.46 Million /m } \\
\text { Total construction cost: KRW } 25.87 \text { Million /m }\end{array}$ & - Cross section of stream and road \\
\hline $\begin{array}{c}\text { SCP } \\
\text { GIRDER }\end{array}$ & $40.0 \mathrm{~m}-50.0 \mathrm{~m}$ & $\begin{array}{l}\text { Superstructure: KRW } 15.174 \text { Million /m } \\
\text { Substructure: KRW 8.106 Million /m } \\
\text { Total construction cost: KRW 23.28Million/m }\end{array}$ & - Cross section of stream and road \\
\hline
\end{tabular}

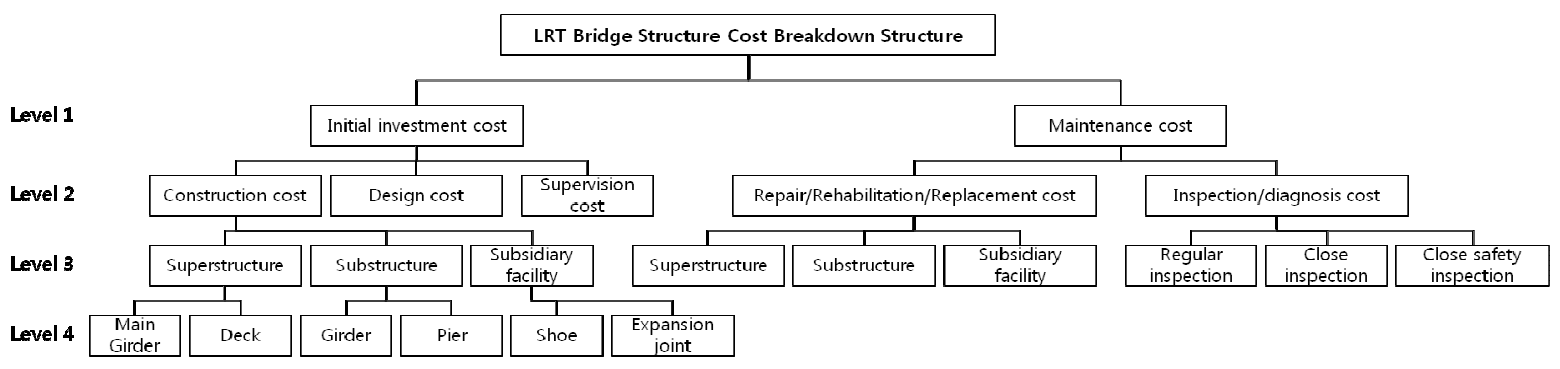

Figure 1. Cost Classification for Railroad Bridge (Source: Du-heon Lee, 2006)

Table 3. Maintenance Application Cycle and Cost for a Bridge(Source: Du-heon Lee, 2006)

\begin{tabular}{|c|c|c|c|c|c|c|c|c|c|c|c|c|}
\hline \multirow[b]{2}{*}{ 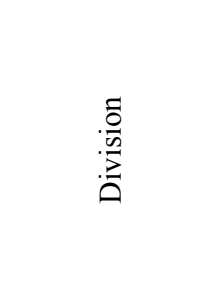 } & \multirow[b]{2}{*}{ Type } & \multicolumn{5}{|c|}{ Cycle Type } & \multirow[b]{2}{*}{ 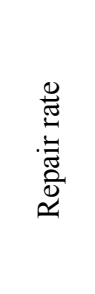 } & \multirow{2}{*}{ 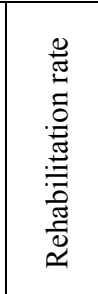 } & \multirow{2}{*}{ 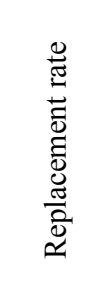 } & \multirow{2}{*}{ 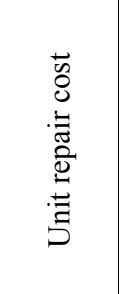 } & \multirow{2}{*}{ 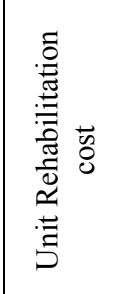 } & \multirow{2}{*}{ 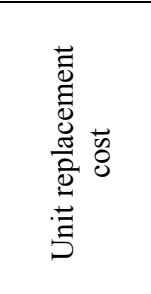 } \\
\hline & & 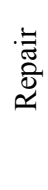 & 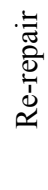 & 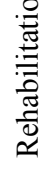 & 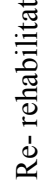 & 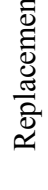 & & & & & & \\
\hline \multirow{5}{*}{ 它 } & PSC Beam & 10 & 8 & 19 & 11 & & $18.4 \%$ & $21.6 \%$ & - & 124.248 & 346.000 & \\
\hline & PSC Box Girder & 10 & 8 & 20 & 12 & & $18.4 \%$ & $21.6 \%$ & - & 124.248 & 346.000 & \\
\hline & Steel Box Girder & 10 & 7 & 20 & 12 & & $19.1 \%$ & $19.8 \%$ & - & 151.889 & 321.453 & $392.180 / \mathrm{m}^{2}$ \\
\hline & IPC Girder & 8 & 7 & 20 & 11 & & $18.4 \%$ & $21.6 \%$ & - & 124.248 & 346.000 & \\
\hline & PF Beam & 9 & 8 & 20 & 13 & & $18.4 \%$ & $21.6 \%$ & - & 124.248 & 346.000 & \\
\hline \multirow{5}{*}{$\begin{array}{l}\text { ù } \\
\text { Oू }\end{array}$} & PSC Beam & 18 & 15 & 25 & 23 & & $21.0 \%$ & $22.3 \%$ & - & 150.220 & 249.366 & \\
\hline & PSC Box Girder & 17 & 14 & 23 & 20 & & $21.0 \%$ & $22.3 \%$ & - & 150.220 & 249.366 & \\
\hline & Steel Box Girder & 18 & 13 & 22 & 21 & & $21.0 \%$ & $22.3 \%$ & - & 150.220 & 249.366 & \\
\hline & IPC Girder & 15 & 12 & 22 & 20 & & $21.0 \%$ & $22.3 \%$ & - & 150.220 & 249.366 & \\
\hline & PF Beam & 15 & 12 & 23 & 20 & & $21.0 \%$ & $22.3 \%$ & - & 150.220 & 249.366 & \\
\hline Shoe & & 8 & 8 & - & - & 22 & $18.3 \%$ & - & $100.0 \%$ & 219.560 & - & $1,199.781$ \\
\hline Expansion joint & & 4 & 4 & - & - & 9 & $20.2 \%$ & - & $100.0 \%$ & \begin{tabular}{|l|}
398.290 \\
\end{tabular} & - & $1,971.733$ \\
\hline \multirow{2}{*}{ Coating } & Interior & & & & & 15 & - & - & - & & & \\
\hline & Exterior & & & & & 13 & - & - & - & & & \\
\hline \multirow[b]{2}{*}{ Substructure } & Pier & 12 & 8 & 23 & 20 & & $28.6 \%$ & $20.6 \%$ & - & 180.180 & 180.180 & \\
\hline & Abutment & 17 & 8 & 23 & 20 & & $24.4 \%$ & $20.6 \%$ & - & 174.870 & 174.870 & \\
\hline
\end{tabular}




\section{RAILROAD STRUCTURE LIFE CYCLE COST ANALYSIS}

\subsection{Factors of Railroad Construction Cost Calculation}

An LCC of an LRT implements an analysis by dividing the process into the pre-design and postdesign stages.

In the pre-design stage, the analysis was performed using the following factors. Deck, orbit, building, electric power, signal, communication, and the streetcar line were used in estimating construction cost. Figure 2 shows the parameters of the deck to calculate life cycle cost. The deck consists of general area and urban area. The parameters of all the items used in calculating life cycle cost vary depending on whether the LRT is to be built in a general area or an urban area, and they are estimated through the length information. However, in the case of a station, the number of stations is input.

In the post-design stage, construction cost and maintenance cost can be calculated by entering detailed design information by structure. In the case of a bridge, a user can enter information of a diagram and level-of-detail, depending on the type of the superstructure or substructure of the bridge as shown in Figure 3 and Figure 4, and based on this information the construction cost and the maintenance cost are calculated. Construction costs for civil structures, tunnels and buildings (stations) are calculated by using the same method as in the pre-design stage.

\subsection{Railroad Life Cycle Cost Analysis Procedure}

The LRT-LCC system developed in this study underwent the procedure shown in Figure 5 to analyze the life cycle cost of an LRT.

Characteristics of a project, such as the expected construction period, expected maintenance period and real discount rate are needed for the life cycle cost analysis. The information on the progress of design is entered here, and the information to be entered and the method to be used vary depending on whether we are in the pre-design or post-design stage.

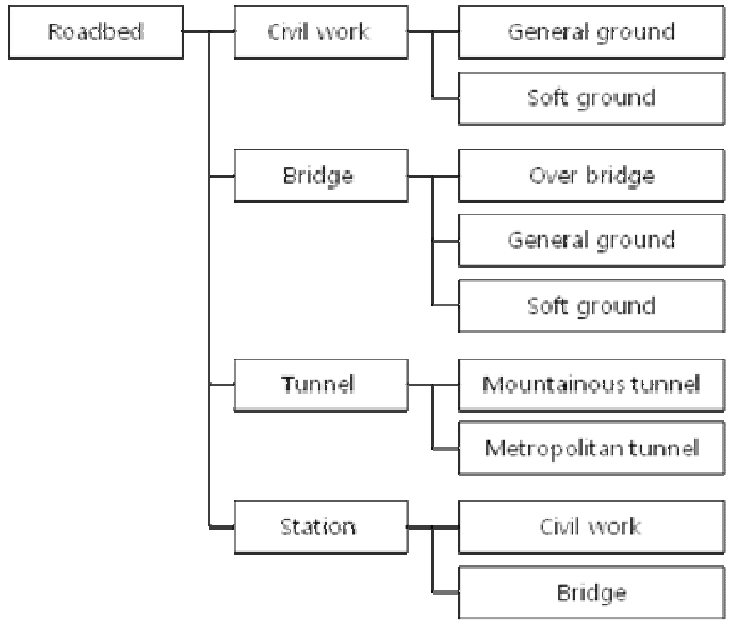

Figure 2. Factors used in calculating life cycle cost for the pre-design stage

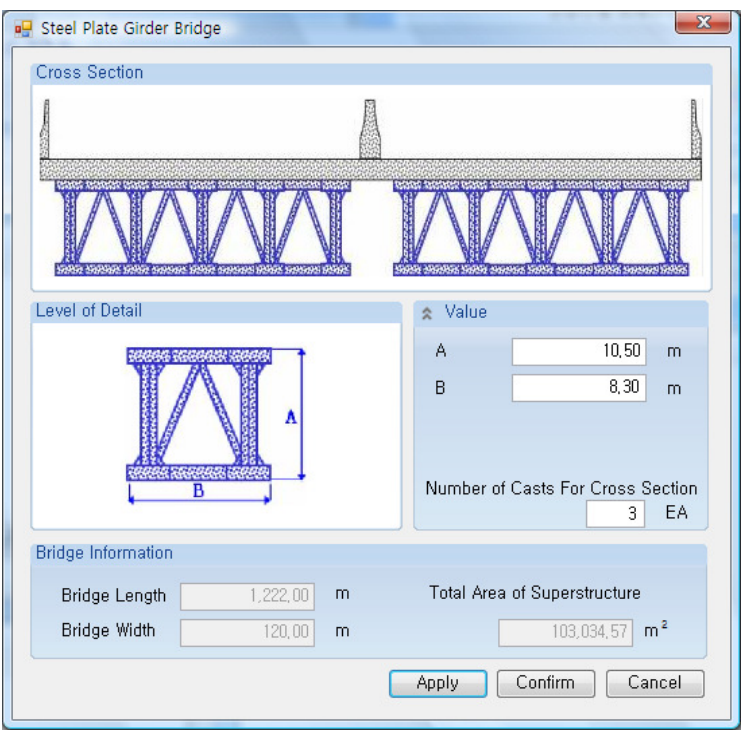

Figure 3. Entering information regarding the upper part of a bridge $^{1}$

${ }^{1}$ The interface LRT-LCC system is designed based on Korean language. The whole interface images of the system on this paper are translated from Korean to English for the readers' convenience. 


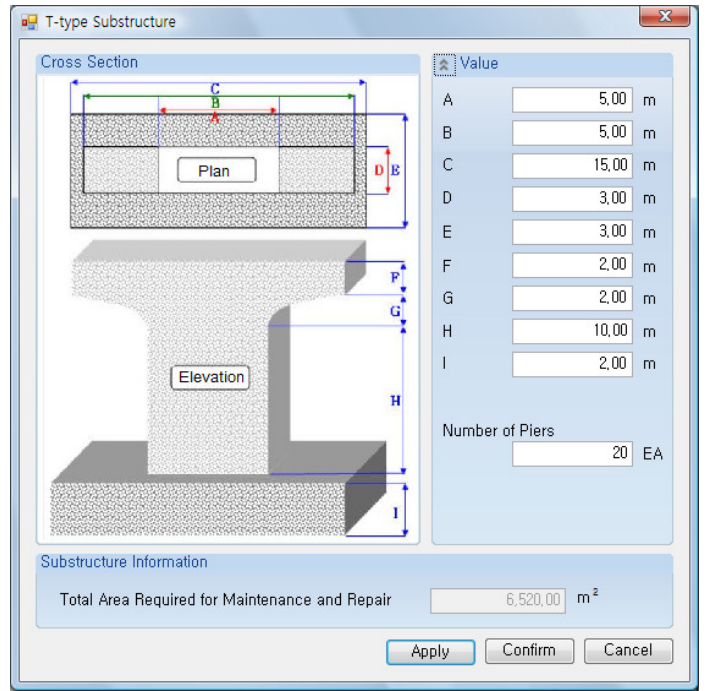

Figure 4. Entering information regarding the substructure of a bridge

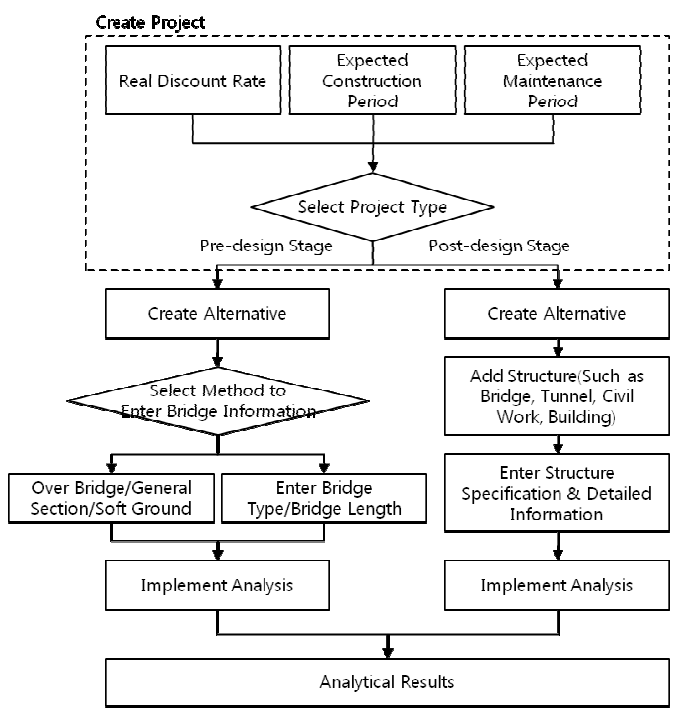

Figure 5. Railroad Life Cycle Cost Analysis Procedure by LRT-LCC

\section{(1) Pre-design Stage}

There are two possible methods of entering bridge information in the pre-design stage. One is to enter the length of the bridge and the bridge's general type, such as Over Bridge, General Ground or Soft Ground. The other is to enter the length and the type of the bridge more specifically. The latter approach makes it possible to analyze with greater accuracy.

Using the standard construction costs for railroad construction shown in Table 1, the initial construction cost is calculated and the construction cost is also calculated by entering each length and place for the blanks.

\section{(2) Post-design Stage}

For the analysis of the post-design stage, a more accurate analysis is possible by entering the structure where an LRT is applied, its type and specification. Figure 6 is a diagram showing the structure types where an LRT is applied, its type, structure and specification to be entered by type.

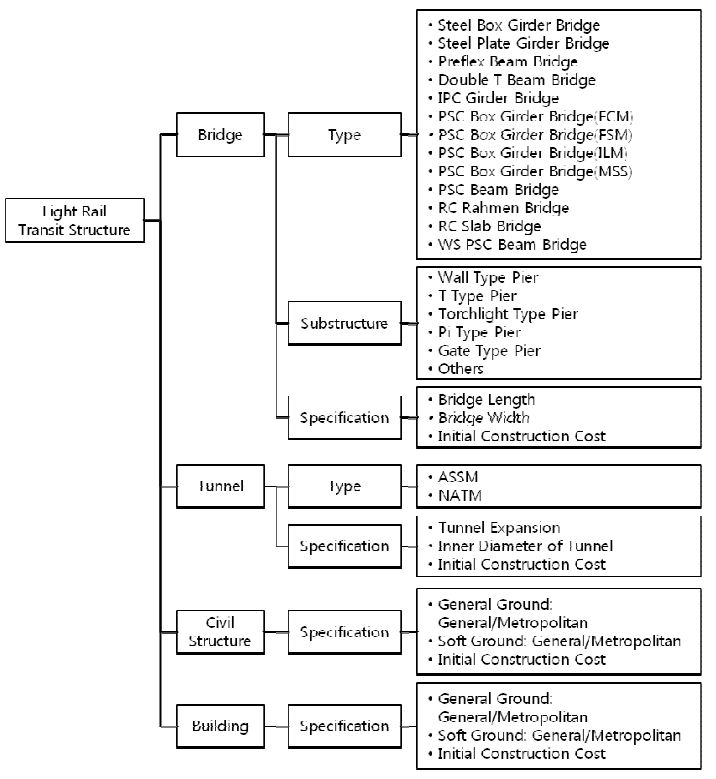

Figure 6. Structure Types for LRT 


\subsection{Maintenance Cost Calculation Method}

(1) Bridge

Based on the study of the OO Light Rail Transit Implementation Plan conducted by Korea Transport Institute in 2001 aforementioned in chapter 2.2, maintenance costs were estimated.

For the post-design stage, application cycles were presumed based on maintenance characteristics according to bridge type, such as repair, re-repair, rehabilitation, re-rehabilitation and replacement. References used for our maintenance cost calculation are as follows (See Table 4):

'A Study on Economic Analysis and Economic Life Cycle Estimation by Bridge Type Using LCC Technique', performed by the Institute of Construction Technology of Chung-Ang University

Analysis data of bridge registers by a subsidiary of Korea Expressway Corporation

Survey data for experts in the 'LCC Analysis Study by Component of Expressway Bridge' conducted by Korea Expressway Corporation in 2002

LCC Analysis Study by Component of Expressway Bridge (2002)

Survey data for experts in the 'LCC Analysis Study by Highway Bridge Type' (2003)

\section{(2) Tunnel}

For tunnels, the maintenance cost for the pre-design stage was calculated based on the same factors used in the bridge study [3-5]. For tunnels, the maintenance cost for the post-design stage was calculated based on general expenses required for a general facility, to which the adjustment weight of Table 4 was applied. (Based on 'Standard Charges for Safety Inspection \& Precise Safety Diagnosis, No. 2003-195', announced by the Ministry of Construction and Transportation on Aug. 3, 2003)

\section{(3) Other Structures}

For civil structures or buildings, a maintenance cost was applied to both the pre-design stage and the post-design stage. The maintenance cost was estimated based on the $\circ \circ$ Light Rail Transit Implementation Plan conducted by the Korea Transport Institute in 2001, as both bridges and tunnels were included in this plan.

Table 4. Weight for Tunnel Maintenance Cost

\begin{tabular}{|c|c|c|c|}
\hline \multicolumn{2}{|c|}{ (1) Adjustment by lane } & \multicolumn{2}{c|}{ (2) Adjustment by purpose } \\
\hline No of lanes & Weight & Purpose & Weight \\
\hline $\begin{array}{c}\text { One-track (2 } \\
\text { lanes) }\end{array}$ & 1.00 & Urban(high speed) & 1.30 \\
$\begin{array}{c}\text { Double-track(3 } \\
\text { lanes) }\end{array}$ & 1.30 & Train & \\
\hline
\end{tabular}

\section{LRT-LCC ANALYSIS SYSTEM}

\subsection{LRT-LCC System Outline}

The process of LRT-LCC is divided into a predesign stage and a post-design process.

(1) Pre-design Stage

The pre-design stage involves performing an economic analysis before an LRT is designed. The pre-design stage is programmed to calculate total construction cost and maintenance cost after a user enters length and location on the divided blanks for deck, orbit, building, electric power, and signal (See Figure 7).

(2) Post-design Stage

The post-design stage involves the performance of a more detailed economic analysis after the LRT has been designed. In order to conduct an analysis for the post-design stage, a user should enter the information of the facilities comprising the LRT, as shown in the figure below. An economic analysis is conducted for each facility, and the LCC can be finally drawn based on the data (See Figure 8).

Information on structures comprising an LRT is entered into the LRT-LCC system by the sections divided as below, and a feasibility analysis is performed, on which the economic feasibility analysis of the entire LRT is based (See Figure 9). 


\begin{tabular}{|c|c|c|c|c|c|}
\hline \multicolumn{6}{|c|}{00 LRT [Alt 1] } \\
\hline \multicolumn{4}{|c|}{ Project Name 00 LRT } & \multicolumn{2}{|c|}{ Alternative Name Alt 1} \\
\hline \multicolumn{3}{|c|}{ Type of Bridge Information } & (- General & Bridge Type & \\
\hline \multicolumn{3}{|c|}{ Division } & General & Metropolitan & Remarks \\
\hline \multicolumn{6}{|c|}{ 1. Cost of Facility } \\
\hline \multirow{9}{*}{$\begin{array}{l}\text { De } \\
\text { ck }\end{array}$} & \multirow{2}{*}{$\begin{array}{l}\text { Civ } \\
\text { iv } \\
\text { wo } \\
r k\end{array}$} & $\begin{array}{l}\text { General } \\
\text { Ground }\end{array}$ & 321 & 122 & \\
\hline & & $\begin{array}{l}\text { Soft } \\
\text { Ground }\end{array}$ & 200 & 30 & \\
\hline & \multirow{3}{*}{$\begin{array}{c}\text { Bri } \\
\mathrm{dg} \\
\mathrm{e}\end{array}$} & $\begin{array}{l}\text { Over } \\
\text { Bridge }\end{array}$ & 25 & 8 & \\
\hline & & $\begin{array}{l}\text { General } \\
\text { Ground }\end{array}$ & 15 & 2 & \\
\hline & & $\begin{array}{l}\text { Soft } \\
\text { Ground }\end{array}$ & 10 & 5 & \\
\hline & \multirow{2}{*}{$\begin{array}{l}\text { Tu } \\
\text { nn } \\
\text { el }\end{array}$} & $\begin{array}{l}\text { Mountaino } \\
\text { us Tunnel }\end{array}$ & 10 & 2 & \\
\hline & & $\begin{array}{l}\text { Metropolita } \\
\text { n Tunnel }\end{array}$ & 5 & 1 & \\
\hline & \multirow{2}{*}{$\begin{array}{c}\text { Sta } \\
\text { tio } \\
n\end{array}$} & Civil Work & 8 & 4 & EA \\
\hline & & Bridge & 2 & & EA \\
\hline \multicolumn{6}{|c|}{ Orbit } \\
\hline \multicolumn{6}{|c|}{ Building } \\
\hline \multicolumn{3}{|c|}{ Electric Power } & 5 & 2 & \\
\hline \multicolumn{3}{|c|}{ Siginal } & 153 & 123 & \\
\hline \multicolumn{3}{|c|}{ Communication } & 12 & 33 & \\
\hline \multicolumn{6}{|c|}{ Streetcar Line } \\
\hline \multicolumn{3}{|c|}{$\begin{array}{l}\text { 2. Incidence } \\
\text { Expenses }\end{array}$} & 50 & 20 & \\
\hline \multicolumn{3}{|c|}{ 3. Land Cost } & & & \\
\hline \multicolumn{6}{|c|}{ Apply Cancel } \\
\hline
\end{tabular}

Figure 7. Entering information for the pre-design stage

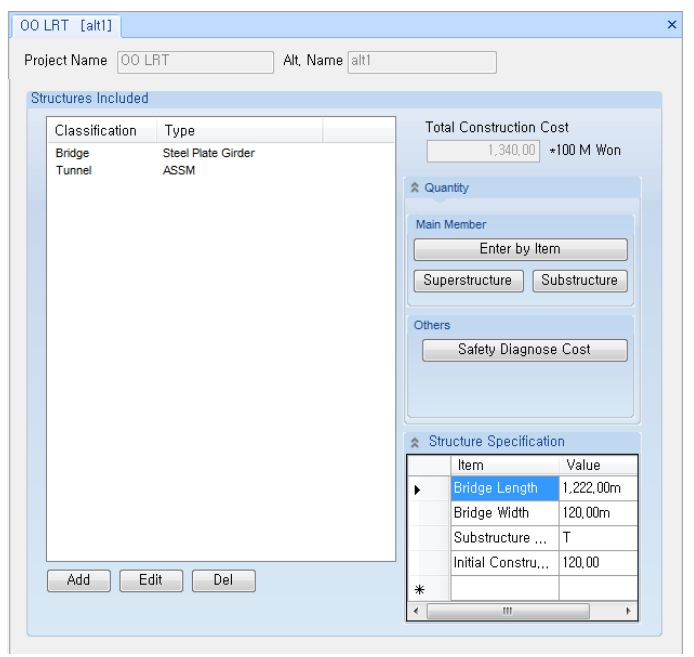

Figure 8. Entering information in the post-design stage

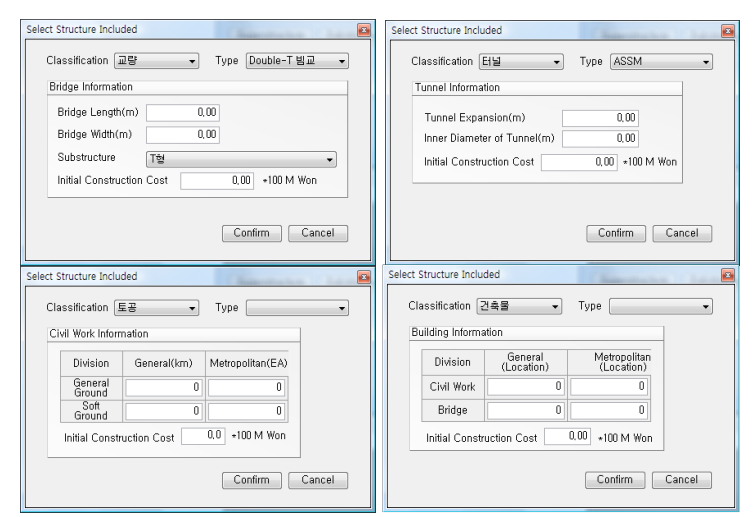

Figure 9. Information Input Interface by Structure Included

\subsection{Development Condition}

The LRT-LCC was developed based on Microsoft's Net 2.0 using VisualBasic.net. It does not support a network, and is operated as standalone software. MS-Access 2007 Database was used to accumulate/manage data. Table 5 shows the system requirements.

Table 5. LRT-LCC System Specification

\begin{tabular}{|c|c|}
\hline Component & Requirements \\
\hline $\begin{array}{c}\text { Computer } \\
\& \\
\text { Processor }\end{array}$ & $500 \mathrm{MHz}$ processor or faster \\
\hline Memory & $\begin{array}{l}\text { 256MB RAM ( } 512 \mathrm{MB} \text { or more } \\
\text { recommended) }\end{array}$ \\
\hline Hard Disk & $\begin{array}{l}10 \mathrm{MB} \text { - when Net framework } 2.0 \text { is not } \\
\text { installed, a disk capacity of } 300 \mathrm{MB}(\mathrm{x} 86) \\
\text { or } 620 \mathrm{MB}(\mathrm{x} 64) \text { is required. }\end{array}$ \\
\hline Display & $\begin{array}{l}\text { Monitor resolution of } 1024 \times 768 \\
\text { (1280x1024 or better recommended) }\end{array}$ \\
\hline $\begin{array}{l}\text { Operating } \\
\text { System }\end{array}$ & $\begin{array}{l}\text { Microsoft Windows XP, Windows Server } \\
2003 \text { SP1 or higher }\end{array}$ \\
\hline $\begin{array}{l}\text { Additional } \\
\text { components }\end{array}$ & $\begin{array}{l}\text { Net framework } 2.0 \text { must be installed. } \\
\text { Actual requirements and product functions } \\
\text { may vary depending on system } \\
\text { composition and operating system }\end{array}$ \\
\hline
\end{tabular}

\subsection{System Structure}

The system developed based on Microsoft NetFramework 2.0 in this study consists of four modules, as shown in Figure 10 below. The database 
is based on Microsoft Access, and OLE DB is used to access to the database.

The database is comprised of two parts: one for the basic data required for the feasibility analysis, and the other for the data entered by the user.

The basic data management module stores and manages the performance data and maintenance cycles necessary for the feasibility analysis.

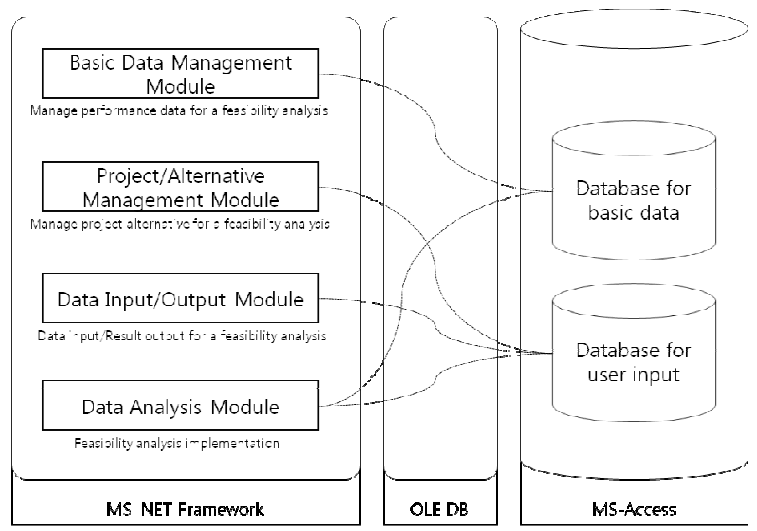

Figure 10. LRT-LCC System Structure

The project alternative management module registers the diverse alternatives for a project, to make it possible to perform an analysis.

The data input-output module reviews the analytical results after entering the data for the feasibility analysis.

The data analysis module provides the result to the user after the feasibility analysis of all entered data has been completed.

\subsection{Database Design}

The LRT-LCC system is designed to implement a feasibility analysis by creating various projects. It provides the function of creating a range of alternatives for a project, and makes it possible to compare the feasibility analysis results obtained by different methods (see Figure 11).

To achieve this, it uses the project table (tblProject), which is the main table, and the alternative management table (tblProjAlt).
The feasibility analysis method and data to be entered may vary depending on whether the project is in the pre-design or the post-design stage. The detailed information of tblProjAlt table has the data property of being able to accumulate and manage the information required to create feasibility analysis results for the pre-design stage.

A feasibility analysis for the post-design stage is conducted based on the information on structures included in the project. This system manages the structural information on the tblProjAltSturcture table, which links to tables such as the bridge information management table (tblProjAltBrdg), the civil structure information management table (tblProjAltCivilWork), the tunnel information management table (tblProjAltTunnel), and the building information management table (tblProjAltBuilding)

There is also a table for safety inspection cost management by structure (tblAltSafetyCheckCost).

For bridges, the information on expansion joint and superstructure of a bridge should be additionally managed, and thus there are the expansion joint table (tblBrdgeExpansionJoint) and tblBrdgSupport table, which allow a user to manage such information on the tables.

\subsection{Interface Design}

The following figure shows the main screen of the LRT-LCC program (see Figure 12). One can easily and conveniently view project names, alternatives and diverse properties on the screen. The detailed information on each alternative is displayed in the middle of the viewing area. If one selects a project or an alternative, its information appears on the main screen.

\subsection{Analytical Results}

The system is programmed to show the analytical results in diverse types of graphs (See Figure 13). A user can have a report produced relating to the analysis he/she wants within a relatively short period of time. 


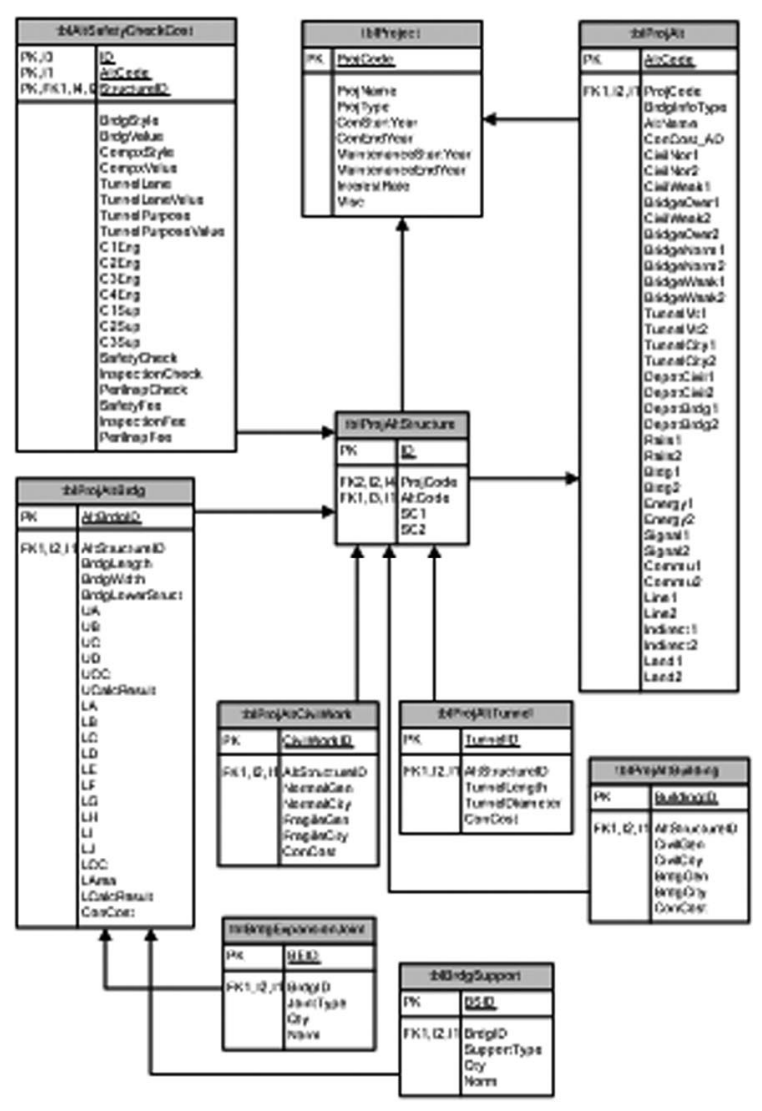

Figure 11. LRT-LCC Database ERD

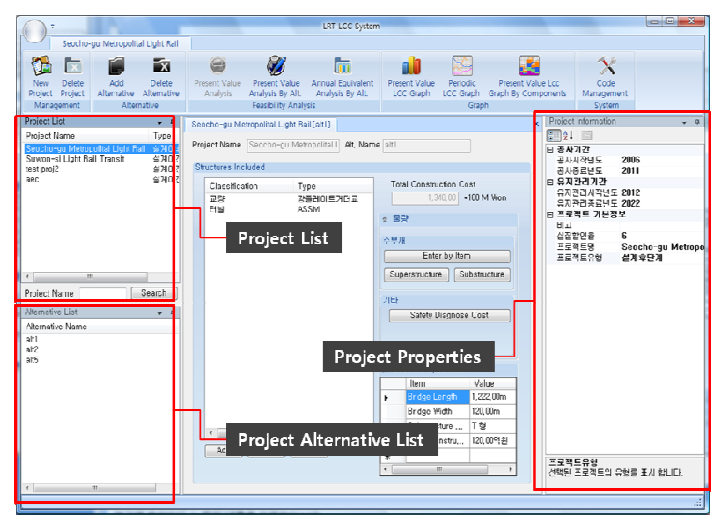

Figure 12. Main Interface of LRT-LCC System

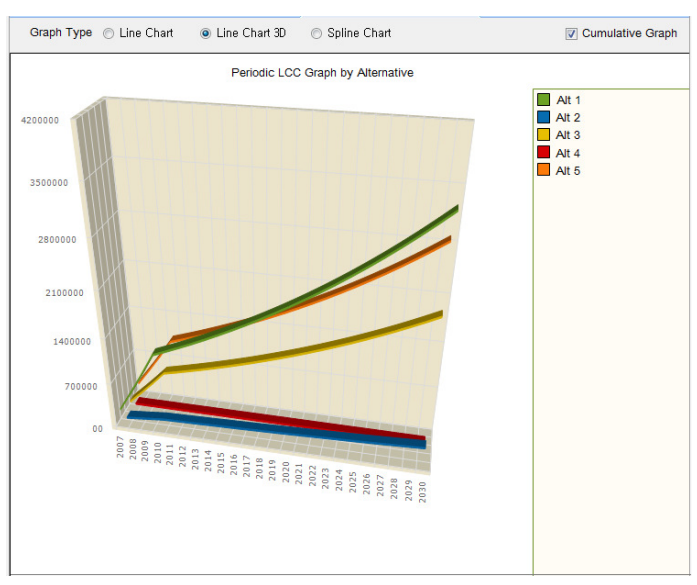

Figure 13. An LCC Analytical Result Graph presented by the LRT-LCC

\section{CONCLUSION}

An LRT-LCC system, an economic analysis system, was developed in this study, based on existing studies on LRT construction cost estimation and LCC estimation studies for bridges, civil structures, and buildings. As there have been no previous LRT constructions in Korea, the system was composed to provide a feasibility analysis based on the existing economic analytical results of each structure required for LRT construction.

This study is significant, in that it systematizes the conventional analysis methods for life cycle cost in a manner that supports a rapid decision-making process in the early stage of an LRT project.

In the future, if the number of LRT construction projects increase and real data on actual construction costs and maintenance costs are accumulated, it will be possible to perform a more accurate analysis. Verification for this LRT-LCC system has not fully performed in this study, and the results drawn by LCC analysis systems or by applying similar cases will be compared with our results to verify the system in follow-up studies.

\section{REFERENCES}

[1] Du-heon Lee, Kyoon-tai Kim, Dong-geun An, Jintaek Jun, Chung-hee Han, "A Study on Life Cycle Cost of Light Rail Transit Bridge", Korea Institute of Construction Engineering and Management Conference Proceeding, Korea Institute of Construction Engineering and Management, 2006, pp. 384-389 
[2] Seo-kyeong Won, Du-heon Lee, Kyoon-tai Kim, Hyeon-bae Kim, Jin-taek Jun, Choong-hee Han, "Precarious Factor Analysis for the Life Cycle Cost of Light Railway Transit Bridge", Korea Institute of Construction Engineering and Management Conference Proceeding, Korea Institute of Construction Engineering and Management, 2007, pp.396-400

[3] Ministry of Construction \& Transportation, Development of Life Cycle Cost Analysis Method and System for the Life-Cycle Cost Optimum Design and the Life-Time Management of Steel Bridges, 2004

[4] Ministry of Construction \& Transportation, Development of Life Cycle Cost Estimation Models and System for Underground Road Structures(Tunnel and Underground Motorway)

[5] Ministry of Construction \& Transportation, Development of Bridge Life Cycle Cost Analysis Model and DataBase, 2002 